\title{
Relationships between Body Condition Score (BCS), FAMACHA@-Score and Haematological Parameters in Alpacas (Vicugna pacos), and Llamas (Lama glama) Presented at the Veterinary Clinic
}

\author{
Matthias Gerhard Wagener ${ }^{1, *(\mathbb{D})}$, Saskia Neubert ${ }^{1}\left(\mathbb{D}\right.$, Teresa Maria Punsmann ${ }^{1}$, Steffen B. Wiegand ${ }^{2}$ \\ and Martin Ganter ${ }^{1}$ (D)
}

1 Clinic for Swine, Small Ruminants, Forensic Medicine and Ambulatory Service, University of Veterinary Medicine Hannover, Foundation, Bischofsholer Damm 15, 30173 Hannover, Germany; Saskia.neubert@tiho-hannover.de (S.N.); opunsma@gmail.com (T.M.P.); Martin.ganter@tiho-hannover.de (M.G.)

2 Department of Anesthesiology, University Hospital, LMU Munich, Marchioninistraße 15, 81377 Munich, Germany; Steffen.wiegand@med.uni-muenchen.de

* Correspondence: Matthias.gerhard.wagener@tiho-hannover.de

Citation: Wagener, M.G.; Neubert, S.; Punsmann, T.M.; Wiegand, S.B.; Ganter, M. Relationships between Body Condition Score (BCS), FAMACHA@-Score and Haematological Parameters in Alpacas (Vicugna pacos), and Llamas (Lama glama) Presented at the Veterinary Clinic. Animals 2021, 11, 2517. https://doi.org/10.3390/ ani11092517

Academic Editors: María-Luz García and María-José Argente

Received: 29 July 2021

Accepted: 24 August 2021

Published: 27 August 2021

Publisher's Note: MDPI stays neutral with regard to jurisdictional claims in published maps and institutional affiliations.

Copyright: (C) 2021 by the authors Licensee MDPI, Basel, Switzerland. This article is an open access article distributed under the terms and conditions of the Creative Commons Attribution (CC BY) license (https:/ / creativecommons.org/licenses/by/ $4.0 /)$.
Simple Summary: Alpacas and llamas are increasingly presented the veterinary clinic in Germany. Owners often notice too late when their animal is emaciated or anaemic. Emaciation can be detected by checking the so-called body condition score (BCS). An indication of anaemia can be provided directly by the FAMACHA@-score (FS), which has been adopted from small ruminants. There is still little information on both scores for alpacas and llamas, so a retrospective evaluation of data from the veterinary clinic was carried out. More than half of the animals admitted to the clinic were too lean and more than one in ten alpacas or one in five llamas showed clinical signs of anaemia. Both scores were compared with the findings from the animals' blood counts, which showed that poor nutritional status was associated with anaemia and shifts in inflammatory cells. Regular monitoring of BCS and FS is therefore important in alpacas and llamas to detect emaciation and anaemia in time.

Abstract: South American camelids (SAC) are being more and more presented at the veterinary Clinics in Germany. A bad nutritional condition, which can be easily categorized using a body condition score (BCS) of the animals, is often not noticed by the owners. Further anaemia is also often only detected in an advanced stage in SAC. Clinical detection of anaemia can be performed by assessing the FAMACHAC-score (FS), that is adapted from small ruminants. So far, there is only little information available about BCS and FS in SAC. In this study, both clinical scores were assessed in alpacas and llamas presented at the veterinary clinic and compared with the haematological parameters from the animals. The data were extracted retrospectively from the animals' medical records and compared statistically. More than half of the alpacas $(60 \%)$ and llamas $(70 \%)$ had a BCS $<3$, while $12 \%$ of the alpacas and $21 \%$ of the llamas had a FS $>2$. A decreased BCS was associated with a decrease in haematocrit, haemoglobin, lymphocytes, and eosinophils, as well as an increase in FS and neutrophils. BCS and FS should be assessed regularly in SAC to detect emaciation and anaemia in time.

Keywords: South American camelids; anaemia; nutritional status; emaciation; clinical scores; haematology

\section{Introduction}

Husbandry of alpacas and llamas (SAC: South American camelids) is becoming more and more popular in Europe [1-3]. However, it remains challenging for the owners to detect health problems. Delayed treatment, especially in connection with malnutrition, is common, since SAC are stoic and have a thick fibre coat, [4]. In some cases, emaciated 
SAC additionally suffer from life-threatening anaemia that requires immediate blood transfusion [5].

Body condition scoring (BCS) is a common clinical tool to detect emaciation in ruminants and SACs [4,6-9]. For clinical detection of anaemia, the close observation of the colour of the mucous membranes, especially the conjunctives, can be used [10,11].

Body condition scoring was originally developed for sheep and dairy cattle [6-8] but has been adapted for SAC. Different body scoring-systems have been evaluated for alpacas and llamas, which include visual and palpatory examination of different body sites such as the lumbar spine, withers, shoulders, ribs, front and rear legs, or the pelvis $[4,9,12-15]$. A scale from 1 to 5 ( $1=$ emaciated; $2=$ thin; $3=$ optimal; $4=$ overweight; $5=$ obese $)$ is commonly used for determination of the nutritional status $[4,15,16]$. An optimal BCS (3) can be characterized by a straight line between the dorsal spinous and transverse processes of the lumbar spine $[15,16]$. A more concave line would be interpreted as a lower BCS, a more convex line as a higher BCS $[15,16]$. Causes for a bad nutritional status in SAC include management problems such as a restricted animal/feeding place ratio, insufficient nutrient supply, infestation with endoparasites, tooth problems, or any other chronical disease [4,17-19]. To date, there are several descriptions about the assessment of BCS in $\mathrm{SAC}$, and there is also some information available about the relationship between BCS and health in llamas and alpacas $[11,19,20]$. However, so far, there is a lack of data concerning the BCS of SAC presented in the veterinary clinic.

In addition to malnutrition, anaemia is frequently observed in SACs [5,11], which is often caused by haemonchosis (Haemonchus contortus) [11,21]. Other reasons for anaemia in llamas and alpacas include haemotroph mycoplasms (Candidatus mycoplasma haemolamae) [22,23], gastric ulcers [24], or undersupply with trace elements that can lead to copper-, cobalt-, or iron deficiency [25-27]. If symptomatic, anaemia can lead to a life-threatening state, requiring immediate treatment [5,28]. Early detection of anaemia is crucial, to monitor the health of a herd and as a marker for anthelmintic treatment response.

The FAMACHAC-score (FS) ("FAMACHA" is an acronym for Dr. Francois "FAffa" MAlan, who created a CHArt with pictures of the conjunctives of sheep with five different red shades) has been established for targeted selective treatment of sheep with haemonchosis [10], which is a major cause of anaemia in sheep. The FS is an easy to use tool, for the clinical detection of anaemia [29]. The different red shades of the chart should be compared with the conjunctives of the animal to be examined and are meant to reflect different packed cell volumes (PCV's). The physiological red colour is expressed as a FS of 1 and the palest, almost white colour as a FS of 5 [10]. FS 1 and 2 are considered as "optimal" and "acceptable", respectively, while FS 3 as "borderline" and FS 4 and 5 as "dangerous" or "fatal" [10]. The FS has been evaluated for small ruminants in many studies worldwide, so far [30-37]. Since the FS targets anaemia and not the potential underlying condition leading to it, scoring of the conjunctives is also suggested as a tool in the diagnosis of other infections that cause anaemia such as fasciolosis [38] or bovine trypanosomosis [39]. Furthermore, there are many other causes for pale conjunctives, for example, acute bleeding.

The FS has also been used as a clinical tool for detecting anaemia in SAC [11,40-43]. Storey et al. investigated the FS in 347 alpacas and 502 llamas on different farms [11]. In 17/21 farms included in their study, Haemonchus contortus was the predominant nematode parasite [21]. They found significant associations between the PCV and FS and between the BCS and faecal egg count (FEC), and concluded that the FS is a useful tool to detect anaemia in SAC suffering from haemonchosis [11].

In ruminants, BCS and FS are well established as common clinical examination methods. They can be collected easily and without complex technical equipment directly on site on the animal. However, there are no data yet on the relationships between the BCS and FS and the haematological parameters for SAC presented to the veterinary clinic. In this study, we evaluated those conditions in alpacas and llamas presented to the clinic, to determine the extent to which clinical findings are associated with laboratory diagnostic parameters. 
In contrast to previously available data collected from animals in herds in the field [11], this study involves data from sick animals. In addition, further haematological parameters such as the individual leukocyte fractions will be considered as a supplement to the previously known data. The resulting findings could provide important information for veterinarians in the field who do not have the possibility of an immediate haematological examination.

\section{Material and Methods}

\subsection{Data Collection}

Relevant data of alpacas and llamas were extracted from the medical files from the archives of the Clinic for Swine, Small Ruminants and Forensic Medicine of the University of Veterinary Medicine Hannover, Germany to an Excel sheet (Microsoft ${ }^{\circledR 囚}$ Excel $^{\circledR \circledast}$ for Office 365). Patient files were archived as paper files until August 2016 and as digital files in the patient management program "easyVET" (VetZ. EasyVET. Available online at: https:/ / www.vetz.vet/de-de/ easyVET, accessed on 29 July 2021) from September 2016 onwards. In this retrospective study, data were assessed between July 2014 and March 2021, since the recording of BCS and FS had been routinely performed during the clinical examination of SAC from July 2014. All the data used in this study were collected during veterinary diagnostic procedures after the owners had given written consent.

\subsection{Inclusion Criteria}

Only animals with information on species, gender, age, BCS, PCV, haemoglobin $(\mathrm{Hb})$, total leucocytes (white blood count: WBC), and with blood smear results for cell differentiation were included in the analysis. The absolute bodyweight in $\mathrm{kg}$ and FS were not recorded for each animal. Therefore, they were only evaluated in a subset of animals.

\subsection{Collected Parameters from the Animals}

\subsubsection{Basic Data about the Animal}

Basic data included the animal's clinic-ID, species (alpaca or llama), gender (female or male), day of examination, animal's birthday, animal's age (in days, calculated by subtracting the animal's birthday from the day of examination), and, if available, the animal's bodyweight in $\mathrm{kg}$.

\subsubsection{Clinical Scores}

Both evaluated clinical scores (BCS and FS) were assessed during the first clinical examination immediately after the animal had been presented to the clinic.

\section{BCS}

The BCS was noted as a score from 1 (emaciated) to 5 (obese) with 0.5 steps in between. BCS was assessed by experienced examiners by palpation of the lumbar spine according to the method described recently [15]. An optimal BCS was defined as 3.

FS

The FS was noted as a score for the colour of the mucous membranes of the conjunctives from 1 (physiological red colour) to 5 (pale, almost white). The red shades in between were expressed as scores 2,3, and 4. FS was assessed by experienced examiners, by presenting the lower palpebral conjunctives. The official FAMACHA@-chard was used for learning the technique, but in most of the cases in the routine the FS was assessed as a subjective impression of the conjunctival colour, without using the colour standard of the card as a direct comparison. A FS $>2$ was defined as a hint of anaemia [10]. In animals with reddened conjunctiva due to conjunctivitis, for example, no FS could be assessed.

\subsubsection{Haematological Parameters}

Routine EDTA-blood samples (EDTA Monovette 9 mL K3E, Sarstedt AG \& Co. KG, Nümbrecht, Germany) were taken from the jugular vein from each animal during the 
general clinical examination [44]. Blood samples were either processed directly or stored at $4{ }^{\circ} \mathrm{C}$ when the animals were presented at night or during the weekend.

$\mathrm{PCV}[\mathrm{L} / \mathrm{L}]$

The packed cell volume (PCV), haematocrit was evaluated by centrifugation of EDTAblood in a microhematocrit tube for $10 \mathrm{~min}$ at $10,000 \times \mathrm{g}$. The PCV was determined as the ratio of the volume of red blood cells divided by the total blood volume.

Haemoglobin $(\mathrm{Hb})[\mathrm{g} / \mathrm{L}]$

$\mathrm{Hb}$ was determined photometrically using a cyan solution [45]. A total of $10 \mu \mathrm{L}$ EDTA blood was added to the $2.5 \mathrm{~mL}$ cyan solution (containing $18 \mathrm{mmol} / \mathrm{L}$ sodium hydrogen carbonate, $0.768 \mathrm{mmol} / \mathrm{L}$ potassium cyanide, $0.608 \mathrm{mmol} / \mathrm{L}$ potassium ferricyanide) in a cuvette. The solution was incubated for $5 \mathrm{~min}$ and then measured with a photometer $(546 \mathrm{~nm}) . \mathrm{Hb}$ in $\mathrm{g} / \mathrm{L}$ was determined by multiplying the determined extinction with the factor 368 .

\section{Total Leucocytes/White Blood Count (WBC) [G/L]}

WBC was determined microscopically in a Neubauer counting chamber after $5 \mathrm{~min}$ lysis of $100 \mu \mathrm{L}$ EDTA blood in $900 \mu \mathrm{L} 3 \%$ acetic acid solution [45]. If normoblasts were observed in the subsequent differentiation of the blood smear, the total leukocyte count was mathematically corrected according to the following formula: $\mathrm{WBC}[\mathrm{G} / \mathrm{L}]=$ number of nuclei counted in the Neubauer chamber $[G / L] \times 100 /(100+$ Number of normoblasts per 100 leukocytes).

Lymphocytes, Segmented Neutrophils, Band Neutrophils, Eosinophils, Basophils, Monocytes, Normoblasts, all [\%]

Differentiation of leucocytes was performed microscopically in a blood smear stained according to Pappenheim. In each blood smear, 200 leukocytes were differentiated according to their morphological features and assigned to lymphocytes, segmented neutrophils, band neutrophils, eosinophils, basophils, and monocytes. Normoblasts (nucleated red blood cells) that occurred during differentiation were recorded in addition to the 200 leucocytes.

\subsection{Statistical Analysis}

Statistical tests were performed using SAS Enterprise Guide 7.1. Descriptive statistics were expressed as median (med), mean, standard deviation (SD), minimum (min), maximum (max), lower quartile (LQ), and upper quartile (UQ) of the investigated parameters in each group. Normal distribution was tested with the Shapiro-Wilk test.

The Wilcoxon-two-sample-test was used to test for statistical differences between alpacas and llamas, as well as differences in gender (male or female) or age (crias $[<1$ year] or adults [ $>1$ year]) for both species separately. Furthermore, anaemic and non-anaemic animals were compared separately in both species. The reference values of Hengrave-Burri et al. [46] were used to categorize anaemic and non-anaemic animals. Animals whose PCV were below the corresponding lower reference value (alpacas: All crias: $0.29 \mathrm{~L} / \mathrm{L}$, adult males: $0.29 \mathrm{~L} / \mathrm{L}$, adult females: $0.26 \mathrm{~L} / \mathrm{L}$; llamas: All crias: $0.28 \mathrm{~L} / \mathrm{L}$, adult males: $0.29 \mathrm{~L} / \mathrm{L}$; adult females: $0.27 \mathrm{~L} / \mathrm{L}$ ) were classified as anaemic, while all other animals were classified as non-anaemic.

The Kruskal-Wallis test was used to determine differences for different BCS or FS. Spearman's rank correlation coefficient was used for calculating correlations between the investigated parameters and BCS or FS.

A p-value less than 0.05 was considered significant $\left(^{*}=p<0.05 ;{ }^{*}=p<0.01\right.$; $* * *=p<0.001$ ). Significant correlations were interpreted as follows: $\mathbf{R}=0.2-0.3$ : Very weak correlation; $\mathrm{R}=0.3-0.5$ : Weak correlation; $\mathrm{R}=0.5-0.8$ : Moderate correlation; $\mathrm{R}>0.8$ : Strong correlation. Since most of the investigated groups had a value of $p<0.05$ in the 
Shapiro-Wilk test and therefore, failed normal distribution, nonparametric tests were performed. In the descriptive data (Supplementary Material), both the median and mean were given, since the differences in the mean were more obvious.

\section{Results}

\subsection{Population}

The total number of all animals $(\mathrm{N}=300)$ was further divided into the species (al-paca (A) or llama (L)), gender (male or female), and the age (crias: < 1 year; adults: > 1 year). A total of 10 different groups were considered:

All alpacas $(n=259)$

All llamas $(\mathrm{n}=41)$

Alpacas, male, cria $(\mathrm{n}=26)$

Alpacas, male, adult $(n=87)$

Alpacas, female, cria $(n=40)$

Alpacas, female, adult $(\mathrm{n}=106)$

Llamas, male, cria $(\mathrm{n}=2)$

Llamas, male, adult $(\mathrm{n}=21)$

Llamas, female, cria $(\mathrm{n}=2)$

Llamas, female, adult $(\mathrm{n}=16)$

\subsection{Clinical Parameters}

\subsubsection{BCS}

About $60 \%$ of the alpacas $(n=154 / 259)$ and $70 \%$ of the llamas $(n=29 / 41)$ had a BCS of lower than three. Alpaca crias showed a lower BCS than adult alpacas, with no differences between species or gender (Tables 1 and S1-S4). Alpacas or llamas with anaemia had a lower BCS than alpacas and llamas without anaemia (Tables 1, S5 and S6). When comparing animals with different BCS, there were significant differences in bodyweight, FS, PCV, Hb, and eosinophils in both species (Tables S7 and S8). In llamas, there were additionally differences in lymphocytes, segmented neutrophils, and basophils depending on the BCS of the animal (Tables S7 and S8).

Table 1. Results of the Wilcoxon test to check for differences in species (alpacas vs. llamas), gender (male vs. female), age (juvenile vs. adult), and presence of anaemia (anaemia vs. without anaemia). No data on the influence of age are available for llamas, since the juvenile llamas group contained only two animals. There were no significant differences between male and female animals for any of the parameters. ${ }^{*}=p<0.05 ;{ }^{* *}=p<0.01{ }^{* * *}=p<0.001$; n.s. $=$ not significant.

\begin{tabular}{|c|c|c|c|c|}
\hline \multirow[t]{2}{*}{ Parameter } & \multirow{2}{*}{$\begin{array}{c}\text { Alpaca vs. } \\
\text { Llama } \\
\text { All }\end{array}$} & \multirow{3}{*}{ 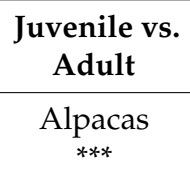 } & \multicolumn{2}{|c|}{$\begin{array}{c}\text { Anaemia vs. } \\
\text { without Anaemia }\end{array}$} \\
\hline & & & Alpacas & Llamas \\
\hline Bodyweight (kg) & $* * *$ & & $* * *$ & $* * *$ \\
\hline $\mathrm{BCS}$ & n.s. & $* *$ & $* * *$ & $* * *$ \\
\hline FS & n.s. & * & $* *$ & $* * *$ \\
\hline $\mathrm{PCV}(\mathrm{L} / \mathrm{L})$ & n.s. & n.s. & $* * *$ & $* * *$ \\
\hline $\mathrm{Hb}(\mathrm{g} / \mathrm{L})$ & n.s. & n.s. & $* * *$ & $* * *$ \\
\hline $\mathrm{WBC}(\mathrm{G} / \mathrm{L})$ & n.s. & n.s. & n.s. & n.s. \\
\hline Lymphocytes (\%) & $* *$ & $* * *$ & n.s. & n.s. \\
\hline Segmented neutrophils (\%) & n.s. & $* *$ & n.s. & n.s. \\
\hline Band neutrophils (\%) & n.s. & n.s. & * & n.s. \\
\hline Eosinophils (\%) & n.s. & $* *$ & n.s. & $* *$ \\
\hline Basophils (\%) & n.s. & n.s. & n.s. & n.s. \\
\hline Monocytes (\%) & n.s. & n.s. & * & n.s. \\
\hline Normoblasts (\%) & n.s. & n.s. & n.s. & * \\
\hline
\end{tabular}


BCS in alpacas correlated a weak positive correlation with bodyweight and very weak with PCV, Hb, and eosinophils (Tables 2 and S9). A weak negative correlation was observed for BCS and FS (Tables 2 and S9).

Table 2. Results of Spearman's correlation for BCS, FS, and PCV with the investigated clinical and haematological parameters in alpacas $(\mathrm{n}=259) .{ }^{*}=p<0.05 ;{ }^{* * *}=p<0.001 ;$ n.s. $=$ not significant.

\begin{tabular}{ccccccc}
\hline Alpacas & \multicolumn{2}{c}{ BCS } & \multicolumn{2}{c}{ FS } & \multicolumn{2}{c}{ PCV } \\
\hline & $\mathrm{r}=$ & & $\mathrm{r}=$ & & $\mathrm{r}=$ & \\
Bodyweight (kg) & 0.41 & $* * *$ & 0.03 & $\mathrm{n} . \mathrm{s}$. & 0.16 & $*$ \\
BCS & & & -0.32 & $* * *$ & 0.29 & $* * *$ \\
FS & -0.32 & $* * *$ & & & -0.34 & $* * *$ \\
PCV (L/L) & 0.29 & $* * *$ & -0.34 & $* * *$ & & \\
Hb (g/L) & 0.28 & $* * *$ & -0.32 & $* * *$ & 0.94 & $* * *$ \\
WBC (G/L) & -0.08 & n.s. & -0.08 & n.s. & 0.00 & n.s. \\
Lymphoytes (\%) & 0.09 & n.s. & -0.08 & n.s. & 0.12 & $*$ \\
Segmented neutrophils (\%) & -0.08 & n.s. & 0.04 & n.s. & -0.13 & $*$ \\
Band neutrophils (\%) & -0.12 & n.s. & 0.13 & n.s. & 0.08 & n.s. \\
Eosinophils (\%) & 0.28 & $* * *$ & -0.11 & n.s. & -0.10 & n.s. \\
Basophils (\%) & 0.11 & n.s. & -0.12 & n.s. & -0.13 & $*$ \\
Monocytes (\%) & 0.06 & n.s. & 0.03 & n.s. & 0.22 & $* * *$ \\
Normoblasts (\%) & -0.09 & n.s. & 0.26 & $* * *$ & -0.20 & $* * *$ \\
\hline
\end{tabular}

In llamas, BCS correlated a moderate positive correlation with bodyweight, PCV, $\mathrm{Hb}$, lymphocytes, and eosinophils, whereas FS and segmented neutrophils revealed a negative correlation with BCS in llamas (Tables 3 and S9).

Table 3. Results of Spearman's correlation for BCS, FS, and PCV with the investigated clinical and haematological parameters in llamas $(\mathrm{n}=41) .{ }^{*}=p<0.05 ;{ }^{* *}=p<0.01{ }^{* * *}=p<0.001$; n.s. $=$ not significant.

\begin{tabular}{ccccccc}
\hline Llamas & \multicolumn{2}{c}{ BCS } & \multicolumn{2}{c}{ FS } & \multicolumn{2}{c}{ PCV } \\
\hline & $\mathrm{r}=$ & & $\mathrm{r}=$ & & $\mathrm{r}=$ & \\
Bodyweight (kg) & 0.66 & $* * *$ & -0.36 & $*$ & 0.56 & $* * *$ \\
BCS & & & -0.55 & $* * *$ & 0.59 & $* * *$ \\
FS & -0.55 & $* * *$ & & & -0.73 & $* * *$ \\
PCV (L/L) & 0.59 & $* * *$ & -0.73 & $* * *$ & & \\
Hb (g/L) & 0.60 & $* * *$ & -0.72 & $* * *$ & 0.96 & $* * *$ \\
WBC (G/L) & -0.25 & n.s. & -0.06 & n.s. & 0.18 & n.s. \\
Lymphoytes (\%) & 0.54 & $* * *$ & -0.17 & n.s. & 0.07 & n.s. \\
Segmented neutrophils (\%) & -0.46 & $* *$ & 0.25 & n.s. & -0.16 & n.s. \\
Band neutrophils (\%) & -0.13 & n.s. & 0.22 & n.s. & -0.15 & n.s. \\
Eosinophils (\%) & 0.61 & $* * *$ & -0.54 & $* * *$ & 0.50 & $* * *$ \\
Basophils (\%) & 0.25 & n.s. & -0.04 & n.s. & 0.09 & n.s. \\
Monocytes (\%) & -0.01 & n.s. & -0.05 & n.s. & 0.05 & n.s. \\
Normoblasts (\%) & -0.30 & n.s. & 0.54 & $* * *$ & -0.53 & $* * * *$ \\
\hline
\end{tabular}

\subsubsection{FS}

About $12 \%(n=24 / 214)$ of the investigated alpacas and $21 \%(n=8 / 39)$ of the investigated llamas had an FS $>2$. When comparing species or gender separately for each species, there were no significant differences regarding FS (Tables 1, S1, S2 and S4), but there was an effect of age in alpacas: Crias had a lower FS than adult alpacas (Tables 1, S1 and S3). In both species, animals with anaemia had a significantly higher FS than animals without anaemia (Tables 1, S5 and S6). Different FS were associated with differences in BCS, PCV, $\mathrm{Hb}, \mathrm{MCHC}$, lymphocytes, eosinophils, and normoblasts in alpacas and with differences in BCS, PCV, Hb, eosinophils, and normoblasts in llamas (Tables S10 and S11).

In alpacas, weak negative correlations were found between FS and BCS, PCV and $\mathrm{Hb}$, and a very weak positive correlation between FS and normoblasts (Tables 2 and S12). In 
llamas, moderate negative correlations were found between FS and BCS, PCV, $\mathrm{Hb}$, and eosinophils and a weak negative correlation between FS and bodyweight. FS in llamas further correlated moderate positively with normoblasts (Tables 3 and S12).

\subsection{Haematological Parameters}

\subsubsection{PCV}

When compared with the reference values of Hengrave Burri (2005) [46], the majority of SAC that was presented to the clinic suffered from anaemia ( $55 \%$ of the alpacas, $49 \%$ of the llamas). The lowest PCV in a single alpaca or llama was $0.04 \mathrm{~L} / \mathrm{L}$, the maximal $\mathrm{PCV}$ was $0.43 \mathrm{~L} / \mathrm{L}$ in an alpaca and $0.47 \mathrm{~L} / \mathrm{L}$ in a llama (Table S1). Differences for PCV in species, gender, or age were not statistically significant (Tables 1 and S2-S4). In both alpacas and lamas, a low PCV was found to be associated with a low BCS (Figure 1) and a higher FS (Tables S5 and S6). PCV in alpacas revealed a strong positive correlation with $\mathrm{Hb}$, a weak positive correlation with BCS and monocytes, as well as a weak negative correlation with FS and normoblasts (Tables 2 and S13). PCV in llamas also revealed a strong positive correlation with $\mathrm{Hb}$, a moderate positive correlation with bodyweight, BCS, and eosinophils, as well as a moderate negative correlation with FS and normoblasts (Tables 2 and S13). All the animals with severe anaemia $(\mathrm{PCV}<0.10 \mathrm{~L} / \mathrm{L})$ had a BCS $\leq 3$.

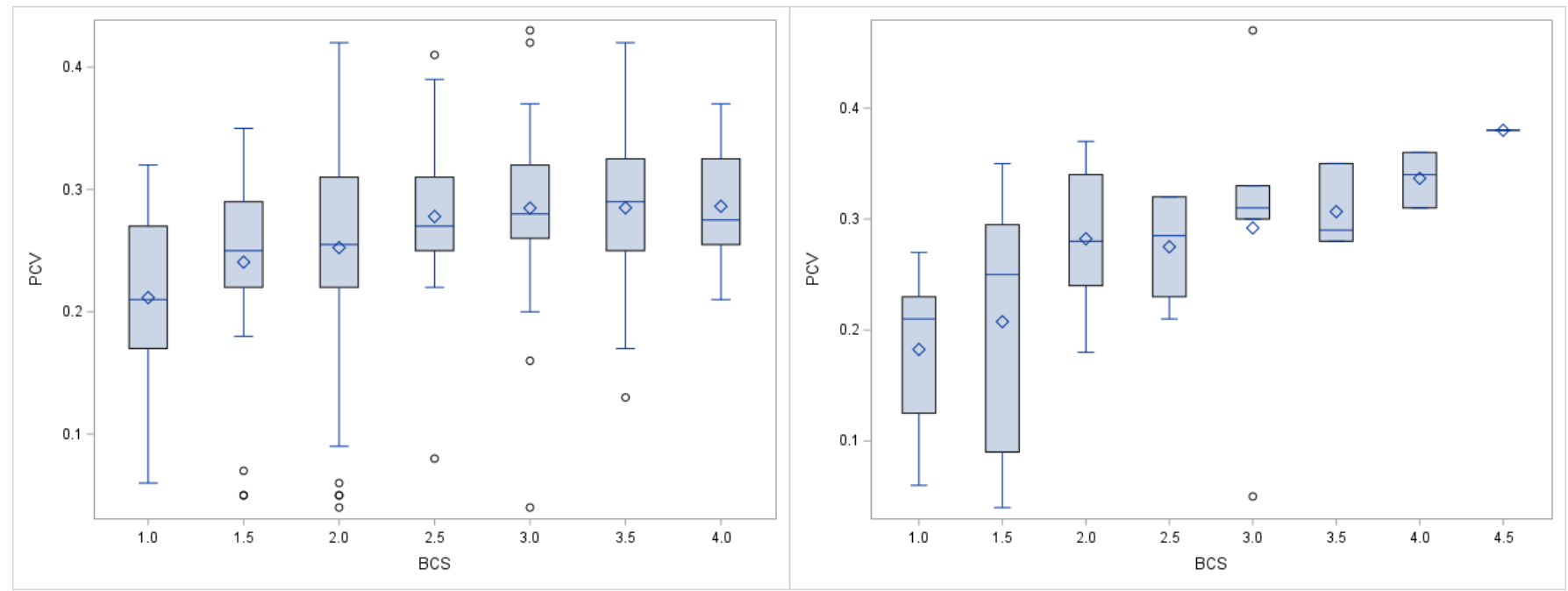

Figure 1. PCV in L/L in alpacas $(n=259$, left) and llamas $(n=41$, right) with different BCS. The boxplots display the quartile range and the respective minimum and maximum.

\subsection{2. $\mathrm{Hb}$}

$\mathrm{Hb}$ in alpacas had a range of 20-198 $\mathrm{g} / \mathrm{L}$, while in llamas, the range was $15-218 \mathrm{~g} / \mathrm{L}$ (Table S1). Since PCV and $\mathrm{Hb}$ showed a very strong correlation, $\mathrm{Hb}$ showed similar associations with the other parameters as PCV (Tables 2 and 3).

\subsubsection{WBC}

The range of WBC was $0.3-75.0 \mathrm{G} / \mathrm{L}$ in alpacas and 2.8-40.4 G/L in llamas (Table S1). Differences in species or gender were not detected, nor was there a difference between alpaca crias and adult alpacas or anaemic and non-anaemic animals (Tables 1 and S2-S5). Influences of different BCS or FS were not evident in the Kruskal-Wallis test (Tables S7 and S10) and correlations with BCS, FS, and PCV did not yield significant results (Tables 2, 3, S9, S12 and S13).

\subsubsection{Lymphocytes}

Lymphocytes revealed a range of $1-90 \%$ in alpacas and 3-65\% in llamas (Table S1). Lymphocyte percentages were higher in alpacas than in llamas and higher in alpaca crias 
than in adult alpacas (Tables 1 and S1-S3). Differences between gender or anaemic and nonanaemic animals were not observed (Tables 1, S4 and S5). The proportion of lymphocytes was different depending on the BCS of the llamas (Tables S7 and S8). BCS and lymphocytes correlated as moderate positive in llamas (Figure 2). However, in alpacas, there was no significant correlation between BCS and lymphocytes (Tables 3 and S9).
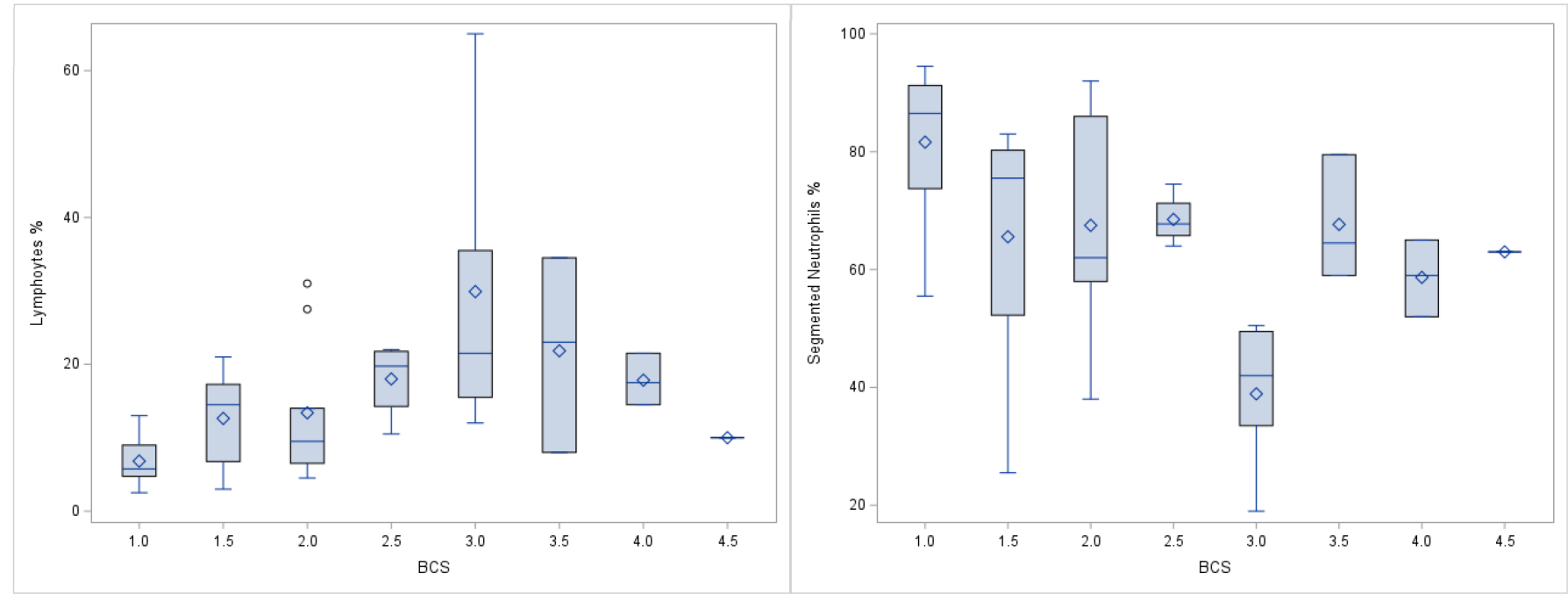

Figure 2. Proportions of lymphocytes (left) and segmented neutrophils (right) in llamas $(\mathrm{n}=41)$ with different BCS. The boxplots display the quartile range and the respective minimum and maximum.

\subsubsection{Neutrophils}

The segmented neutrophils' ranges were 3-98\% in alpacas and 19-95\% in llamas (Table S1). The proportion of segmented neutrophils in alpaca crias was lower than in adult alpacas (Tables 1, S1 and S3), but there were no statistical differences between species, gender, or animals with and without anaemia for segmented neutrophils (Tables 1 , S2, S4 and S5). For band neutrophils, there was a statistical difference between anaemic and non-anaemic animals in alpacas. However, the numerical proportion of band neutrophils was lower in anaemic alpacas than in alpacas without anaemia, whereas the opposite was the case in llamas.

In llamas, BCS was associated with segmented neutrophils (Table S7). Segmented neutrophils in llamas with BCS of 1 revealed the highest median and segmented neutrophils in llamas with BCS 3 the lowest (Table S8 and Figure 2). The correlation between BCS and segmented neutrophils in llamas was weak negative (Tables 3 and S9), however, this was seen only in lamas, not in alpacas (Tables 2 and S9). Different segmented neutrophils were not reflected in the FS of alpacas or llamas (Tables S10-S12).

\subsubsection{Eosinophils}

The percentages of eosinophils were $0-30 \%$ in alpacas and $0-39 \%$ in llamas (Table S1). There were no differences in eosinophils concerning species or gender (Tables S2 and S4), but adult alpacas had significantly higher amounts of eosinophils than alpaca crias (Tables 1 and S3). In addition, llamas with anaemia had a lower percentage of eosinophils than llamas without anaemia. However, this relationship was not seen in alpacas (Tables 1, S5 and S6). In both species, a relationship between BCS and the proportion of eosinophils existed, with both alpacas and llamas having the lowest median of eosinophils at BCS 1 (Tables S7 and S8). The correlation between BCS and eosinophils was stronger in llamas than in alpacas (Tables 2, 3 and S9). Different FS went in hand with different proportions of eosinophils. Nonetheless, this was only significant for llamas (Tables S10 and S11) and was also reflected in a moderate negative correlation between FS and eosinophils in llamas 
(Tables 3 and S12). Further eosinophils in llamas correlated moderately positively with PCV (Tables 3 and S13).

\subsubsection{Basophils}

Basophils had a range of $0-4 \%$ in alpacas and $0-3 \%$ in llamas (Table S1). There were no statistical differences concerning species, gender, and age or between anaemic and nonanaemic animals (Tables 1 and S2-S5). However, BCS was associated with the proportion of basophils in llamas (Table S7). Nevertheless, there were no significant correlations between basophils and BCS, FS or PCV in either species (Tables 2, 3, S9, S12 and S13).

\subsubsection{Monocytes}

The monocyte ranges were $0-21 \%$ for alpacas and $0-9 \%$ for llamas (Table S1). There were no statistical differences between species, age, or gender (Tables 1 and S2-S4), but alpacas with anaemia revealed lower proportions of monocytes in the differential count than alpacas without anaemia (Tables 1, S5 and S6). However, this was not the case in llamas. Different BCS or FS were not reflected in the proportion of monocytes (Tables S10 and S11) and there were no significant correlations between monocytes and BCS, FS, or PCV in alpacas or llamas (Tables 2, 3, S9, S12 and S13).

\subsubsection{Normoblasts}

Normoblasts were present in 33\% ( $n=85 / 259)$ of the alpacas and $34 \%(n=14 / 41)$ of the llamas. Species, gender, and age had no effect on normoblasts (Tables 1 and S2-S4). In anaemic llamas, the amount of normoblasts was higher than in non-anaemic llamas (Tables 1, S5 and S6). However, this was not statistically significant for alpacas. Different BCS had no impact on normoblasts, but FS was connected to normoblasts (Tables S7, S8, S10 and S11). This was also reflected in a positive correlation between FS and normoblasts, that was moderate in llamas but only very weak in alpacas (Tables 2, 3 and S12). Normoblasts further correlated negatively with PCV in both species (Tables 2, 3 and S13).

\section{Discussion}

We found that most of the llamas and alpacas presented to the clinic had a low BCS and about half of all alpacas and llamas were anaemic. For the clinical parameters, we showed that a low BCS was associated with lower body weight and increased FS in both species. When comparing this with the haematological parameters, a low BCS was also associated with decreased PCV, Hb, and eosinophils in both species. In llamas, a low BCS was additionally associated with a lower percentage of lymphocytes and an increased percentage of segmented neutrophils. In addition, despite the different age of the animals, a good correlation of bodyweight and BCS was found in both species.

A main finding in alpacas and llamas at the clinic is that a poor nutritional status is usually related to a low BCS and in most cases anaemia, as well. The condition of the animals is rarely perceived by the owners themselves. One cause for this is the very dense hair coat of SACs. As the owners do not palpate their animals regularly, the emaciation may remain undetected [4]. In a survey among alpaca and llama owners in Germany [1], fewer than half of all participating 255 farms (38.9\%) reported emaciation in their animals from the owners' observation. Anaemia was observed even less frequently: Only 13.3\% of the farms reported anaemia in their animals from their own observation [1], which contrasts with the results of the present study. The numbers cannot be easily compared since the animals presented to the clinic are usually sick and most healthy animals from the herds are never presented to the clinic. However, Storey et al. found a much lower proportion of animals with a BCS $<3$ in their study on alpaca and lama farms than in the present study. Nonetheless, these animals with lower BCS were overrepresented in the group of anaemic animals [11], which is in line with our data. Storey et al. also found a higher proportion of llamas with anaemia than alpacas. Although this disagrees with our 
findings, it could be explained by the fact that mainly animals with pathological conditions are presented to the clinic [11].

For detecting anaemia in SAC with a PCV $\leq 0.17 \mathrm{~L} / \mathrm{L}$ with an FS $\geq 4$, a sensitivity of $50 \%$ and a specificity of $94 \%$ are given by Storey et al. [11]. FS showed a significantly negative correlation with $\mathrm{PCV}, \mathrm{Hb}$, as well as BCS, especially in the llamas.

It should be noted, however, that the PCV determined per FS has a wide range. This range can be explained by the fact that the FS does not specifically assess the PCV as it can also be elevated or depressed due to local inflammatory processes in the conjunctives or circulatory centralisation [34]. In addition, there is also a lack of specific colour scales for SAC. Since the FS was routinely assessed at the clinic by several examiners, this factor of differing expert opinions must also be taken into consideration. No data are available on this for SAC, but the studies by Maia et al. regarding the assessment of different examiners on the FS in sheep and goats indicate that the FS can be collected quite accurately by different persons after adequate training [47]. For everyday clinical practice, a less precise subdivision (for example "physiological red", "pale", and "white") of the FS might be sufficient to gain a first impression of a single animal.

Similar positive correlations of BCS and $\mathrm{PCV}$ or $\mathrm{Hb}$ as found in our study were also described in sheep or cattle. In pre- and post-partum cattle, Rafia et al. determined $r=0.32$ and $r=0.36$ for the correlation of BCS and PCV [48]. Torres-Chable et al. investigated the correlation of BCS and PCV in sheep and found $r=0.39$ [49]. It is also noteworthy that in this present study, none of the animals with a BCS $>3$ had severe anaemia $(<0.10 \mathrm{~L} / \mathrm{L})$.

The association of low BCS and anaemia remains unclear, there could be speculation about atrophy of the bone marrow or chronic inflammation. However, it must also be considered that the animals were usually transported prior to blood sampling and stress reactions can also lead to shifts in leukocyte fractions. Although no statistically relevant associations with WBC and BCS or PCV were found, the shift in the proportions of leukocytes from lymphocytes to segmented neutrophils in animals with low BCS, especially in the llamas, may provide indications for inflammation. A decrease in lymphocytes was also observed in emaciated horses [50].

Reference values play an important role when interpreting laboratory results. The reference values consulted in this study had a lower limit of $0.26-0.29 \mathrm{~L} / \mathrm{L}$ for PCV, depending on species, gender, or age [46], and were thus in a similar range to reference values for alpacas and llamas from other authors [51-53]. In the animals in our study, no differences in PCV were found with respect to age or gender. However, other authors showed that male SAC usually have higher PCV than females [54,55]. This could be due to the fact that our study did not investigate homogeneous groups, but rather data from animals with different pathological conditions. Moreover, this could possibly be the reason why no significant relationships were found between $\mathrm{WBC}$ and the other parameters. However, Rafia et al. found only a very weak negative correlation $(r=-0.15)$ for BCS and WBC in cattle [48]. When interpreting the PCV, it should also be taken into account that the blood samples were usually taken after the animals had been transported. Here, the transport stress could have led to haemoconcentration effects in individual animals.

The positive correlation between BCS and eosinophils remains unclear. In studies on the influence of BCS on haematological parameters in other species, such a relationship was not reported $[48,49]$. Since anaemia and poor nutritional status are often associated with endoparasites in alpacas [11,21], a negative correlation was expected. It could be speculated here that animals with a lower BCS are in a more immunologically inactive state, which is particularly reflected in the number of eosinophils. However, evidence for this assumption is lacking.

A lower percentage of monocytes in anaemic animals could be due to infection or stress. Nonetheless, since monocytes are generally present in low numbers in a blood smear, a single over- or under-recognized cell during differentiation can account for a large error. The same also applies to the basophils, which are typically found only very sporadically in the blood smear. 
Normoblasts or erythroblasts are usually associated with regenerative anaemia, but there are only few exceptions where normoblasts may appear in the peripheral blood in the absence of anaemia [56]. Although there was a clear negative correlation between PCV and normoblasts, it remains questionable why normoblasts were found equally in anaemic and non-anaemic alpacas. Normoblasts can be present in large numbers in alpacas with highly regenerative anaemia, where extramedullary haematoopoiesis seems to play a role [57]. However, there are still too few data on normoblasts in alpacas in general, and more research is needed. Another haematological parameter that provides information about regeneration is the reticulocyte count [58], but this was only determined in some of the animals investigated in our study and was excluded from the evaluation due to the low number.

\section{Limitations}

The focus of this study was to compare clinical scores (BCS and FS) with haematological findings. Therefore, this does not allow a general statement concerning individual clinical pictures. It is also not possible to draw a conclusion whether a lower BCS was the cause of haematological changes, or whether the BCS was changed as a result of changes that were visible in the blood count. Furthermore, the results of faecal egg counts were not considered. Several animals presented to the clinic had already been dewormed by other veterinarians or by the owners themselves, shortly before presentation at the clinic. This made it impossible to determine the overall contributory of endoparasites to the clinical picture. The clinical diagnoses of the animals were not taken into account in the evaluation. It was not possible to define a main diagnosis for every animal, as some animals had more than one diagnoses. Common diagnoses besides emaciation or anaemia included recumbency or gastric ulcers. Data on pregnancy stage or lactation were also not available for all the animals. Therefore, these parameters were not taken into account.

\section{Conclusions}

In summary, more than half of the alpacas and llamas presented to the clinic had a BCS $<3$. In addition, half of the animals suffered from anaemia. A low BCS was predominantly associated with increased FS and decreased PCV and Hb. There was also evidence that a low BCS was associated with an increase in segmented neutrophils, which may indicate that animals with lower BCS are more likely to be affected by inflammatory diseases.

It is important to educate SAC owners about the fact that a poor nutritional status is closely associated with pathological haematological findings, and to encourage them to check the nutritional status of the animals regularly, so that emaciation can be detected in time. Recording BCS and FS is also particularly useful for identifying potentially anaemic animals. The early detection of pathological conditions in alpacas and llamas can thus make an important contribution to animal welfare.

Supplementary Materials: The following are available online at https:/ /www.mdpi.com/article/10 .3390 /ani11092517/s1. Table S1: Descriptive statistics of bodyweight, BCS, FS, and haematological parameters in alpacas and llamas; Table S2: Wilcoxon test to compare alpacas and llamas concerning bodyweight, BCS, FS, and haematological parameters; Table S3: Wilcoxon test to compare crias and adults concerning bodyweight, BCS, FS, and haematological parameters in alpacas; Table S4: Wilcoxon test to compare gender concerning bodyweight, BCS, FS, and haematological parameters in alpacas and llamas; Table S5: Wilcoxon test to compare anaemic and non-anaemic animals concerning bodyweight, BCS, FS, and haematological parameters in alpacas and llamas; Table S6: Descriptive statistics of bodyweight, BCS, FS, and haematological parameters in anaemic and non-anaemic alpacas and llamas; Table S7: Kruskal-Wallis test to test the influence of BCS on bodyweight; FS and haematological parameters in alpacas and llamas; Table S8: Descriptive statistics of bodyweight, FS, and haematological parameters in alpacas and llamas with different BCS; Table S9: Spearman's correlation for BCS with bodyweight, FS, and haematological parameters in alpacas and llamas; Table S10: Kruskal-Wallis test to test the influence of FS on bodyweight, BCS, and haematological 
parameters in alpacas and llamas; Table S11: Descriptive statistics of bodyweight, BCS, and haematological parameters in alpacas and llamas with different FS; Table S12: Spearman's correlation for FS with bodyweight, BCS, and haematological parameters in alpacas and llamas; Table S13: Spearman's correlation for PCV with bodyweight, BCS, and haematological parameters in alpacas and llamas.

Author Contributions: Conceptualization, M.G.W.; methodology, M.G.W.; software, M.G.W.; validation, M.G.W. and S.B.W.; formal analysis, M.G.W.; investigation, M.G.W.; resources, M.G.W. and M.G.; data curation, M.G.W. and S.N.; writing-original draft preparation, M.G.W.; writing-review and editing, S.B.W., S.N., T.M.P., and M.G.; visualization, M.G.W.; supervision, M.G.; project administration, M.G.W.; funding acquisition, M.G.W. All authors have read and agreed to the published version of the manuscript.

Funding: This publication was supported by Deutsche Forschungsgemeinschaft and University of Veterinary Medicine Hannover, Foundation within the funding programme Open Access Publishing. Open Access funding enabled and organized by Projekt DEAL.

Institutional Review Board Statement: The study was conducted in accordance with the guidelines of the Declaration of Helsinki and approved by the Animal Welfare Officer of the University of Veterinary Medicine Hannover, Foundation under the registration number TVO-2018-V-66.

Data Availability Statement: The datasets supporting the conclusions of this article are included within the article and its additional file. The raw data used in this study are not publicly available since they are veterinary patient records subject to confidentiality. The raw data are located in the patient archive of the Clinic for Swine, Small Ruminants, Forensic Medicine and Ambulatory Service of the University of Veterinary Medicine Hannover Foundation and were analysed with the permission of the clinic management and the Animal Welfare Officer of the University of Veterinary Medicine Foundation.

Acknowledgments: The authors would like to thank the entire laboratory staff of the Clinic for Swine, Small Ruminants, Forensic Medicine and Ambulatory Service, University of Veterinary Medicine Hannover for their excellent work in preparing the haematological data, as well as the entire clinical staff involved in assessment of the clinical parameters and the care of the animals. The authors further gratefully acknowledge the help of Frances Sherwood-Brock, English editorial office, University of Veterinary Medicine Hannover, Foundation, Germany, for proofreading the manuscript for correct English and Martin Beyerbach of the Department of Biometry, Epidemiology and Information Processing, University of Veterinary Medicine Hannover, Foundation, Germany, for statistical advice.

Conflicts of Interest: The authors declare no conflict of interest.

\section{References}

1. Neubert, S.; von Altrock, A.; Wendt, M.; Wagener, M.G. Llama and Alpaca Management in Germany-Results of an Online Survey among Owners on Farm Structure, Health Problems and Self-Reflection. Animals 2021, 11, 102. [CrossRef]

2. Hengrave Burri, I.; Martig, J.; Sager, H.; Liesegang, A.; Meylan, M. South American Camelids in Switzerland. I. Population, Management and Health Problems. Schweiz. Arch. Für Tierheilkd. 2005, 147, 325-334. [CrossRef]

3. Davis, R.; Keeble, E.; Wright, A.; Morgan, K. South American Camelids in the United Kingdom: Population Statistics, Mortality Rates and Causes of Death. Vet. Rec. 1998, 142, 162-166. [CrossRef]

4. Van Saun, R.J. Nutritional Requirements and Assessing Nutritional Status in Camelids. Vet. Clin. North. Am. Food Anim. Pract. 2009, 25, 265-279. [CrossRef]

5. Wagener, M.G.; Grimm, L.M.; Ganter, M. Anaemia in a Llama (Lama glama): Treatment, Regeneration and Differential Diagnoses. Vet. Rec. Case Rep. 2018, 6, e000638. [CrossRef]

6. Jefferies, B. Body Condition Scoring and Its Use in Management. Tasman. J. Agric. 1961, 32, $19-21$.

7. Ferguson, J.D.; Galligan, D.T.; Thomsen, N. Principal Descriptors of Body Condition Score in Holstein Cows. J. Dairy Sci. 1994, 77, 2695-2703. [CrossRef]

8. Edmonson, A.; Lean, I.; Weaver, L.; Farver, T.; Webster, G. A Body Condition Scoring Chart for Holstein Dairy Cows. J. Dairy Sci. 1989, 72, 68-78. [CrossRef]

9. Johnson, L.W. Llama Nutrition. Vet. Clin. North Am. Food Anim. Pract. 1994, 10, 187-201. [CrossRef]

10. Bath, G.F.; Malan, F.; Van Wyk, J. The "FAMACHA" Ovine Anaemia Guide to assist with the control of haemonchosis. In Proceedings of the 7th Annual Congress of the Livestock Health and Production Group of the South African Veterinary Association, Port Elizabeth, South Africa, 5-7 June 1996; p. 5. 
11. Storey, B.E.; Williamson, L.H.; Howell, S.B.; Terrill, T.H.; Berghaus, R.; Vidyashankar, A.N.; Kaplan, R.M. Validation of the FAMACHA $^{\odot}$ System in South American camelids. Vet. Parasitol. 2017, 243, 85-91. [CrossRef] [PubMed]

12. Hilton, C.; Pugh, D.; Wright, J.; Waldridge, B.; Simpkins, S.; Heath, A. How To Determine and When to Use Body Weight Estimates and Condition Scores in Llamas. Vet. Med. 1998, 93, 1015-1018.

13. Bromage, G. Feeding and Nutrition. In Llamas and Alpacas: A Guide to Management; The Crowood Press Ltd.: Marlborough, UK, 2006; pp. 34-45.

14. Duncanson, G.R. Nutrition and Metabolic Diseases. In Veterinary Treatment of Llamas and Alpacas; CABI: Oxfordshire, UK, 2012; pp. 13-21.

15. Wagener, M.G.; Ganter, M. Body Condition Scoring in South American Camelids. Der Prakt. Tierarzt 2020, 101, $684-696$.

16. Gauly, M. Fütterung. In Neuweltkameliden-Haltung, Zucht, Erkrankungen, 4th ed.; Thieme: Stuttgart, Germany, 2018 ; pp. 46-67.

17. Van Saun, R.J. Nutritional Diseases of Llamas and Alpacas. Vet. Clin. North. Am. Food Anim. Pract. 2009, 25, 797-810. [CrossRef]

18. Baumgartner, W.; Wittek, T.; Gauly, M. Allgemeiner Klinischer Untersuchungsgang. In Klinische Propädeutik der Haus- und Heimtiere, 9th ed.; Enke: Stuttgart, Germany, 2018; pp. 50-68.

19. Proost, K.; Pardon, B.; Pollaris, E.; Flahou, T.; Vlaminck, L. Dental Disease in Alpacas. Part 2: Risk Factors Associated with Diastemata, Periodontitis, Occlusal Pulp Exposure, Wear Abnor-Malities, and Malpositioned Teeth. J. Vet. Intern. Med. 2020, 34, 1039-1046. [CrossRef]

20. Frezzato, G.; Stelletta, C.; Murillo, C.E.P.; Simonato, G.; Cassini, R. Parasitological Survey To Address Major Risk Factors Threatening Alpacas in Andean Extensive Farms (Arequipa, Peru). J. Vet. Med Sci. 2020, 82, 1655-1661. [CrossRef]

21. Edwards, E.E.; Garner, B.C.; Williamson, L.H.; Storey, B.E.; Sakamoto, K. Pathology of Haemonchus contortus in New World Camelids in the Southeastern United States: A Retrospective Review. J. Vet. Diagn. Investig. 2016, 28, 105-109. [CrossRef]

22. Crosse, P.; Ayling, R.; Whitehead, C.; Szladovits, B.; English, K.; Bradley, D.; Solano-Gallego, L. First Detection of 'Candidatus Mycoplasma Haemolamae'infection in Alpacas in England. Vet. Rec. 2012, 171, 71-75. [CrossRef]

23. Kaufmann, C.; Meli, M.; Hofmann-Lehmann, R.; Riond, B.; Zanolari, P. Epidemiology of'Candidatus Mycoplasma Haemolamae'infection in South American Camelids in Central Europe. J. Camelid Sci. 2011, 4, 23-29.

24. Smith, B.B.; Pearson, E.G.; Timm, K.I. Third Compartment Ulcers in the Llama. Vet. Clin. North. Am. Food Anim. Pract. 1994, 10, 319-330. [CrossRef]

25. Foster, A.; Bidewell, C.; Barnett, J.; Sayers, R. Haematology and Biochemistry in Alpacas and Llamas. In Practice 2009, 31, $276-281$. [CrossRef]

26. Andrews, A.; Cox, A. Suspected Nutritional Deficiency Causing Anaemia in Llamas (Lama glama). Vet. Rec. 1997, 140, 153-154. [CrossRef] [PubMed]

27. Morin, D.; Garry, F.; Weiser, M.; Fettman, M.; Johnson, L. Hematologic Features of Iron Deficiency Anemia in Llamas. Vet. Pathol. 1992, 29, 400-404. [CrossRef] [PubMed]

28. Luethy, D.; Stefanovski, D.; Salber, R.; Sweeney, R. Prediction of Packed Cell Volume after Whole Blood Transfusion in Small Ruminants and South American Camelids: 80 Cases (2006-2016). J. Vet. Intern. Med. 2017, 31, 1900-1904. [CrossRef] [PubMed]

29. Van Wyk, J.A.; Bath, G.F. The FAMACHA System for Managing Haemonchosis in Sheep and Goats by Clinically Identifying Individual Animals for Treatment. Vet. Res. 2002, 33, 509-529. [CrossRef]

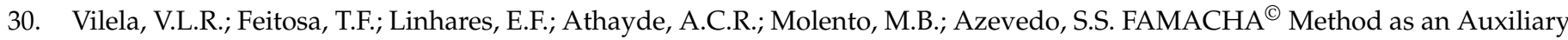
Strategy in the Control of Gastrointestinal Helminthiasis of Dairy Goats Under Semiarid Conditions of Northeastern Brazil. Vet. Parasitol. 2012, 190, 281-284. [CrossRef]

31. Gauly, M.; Schackert, M.; Erhardt, G. Use of FAMACHA ${ }^{\circledR}$ Scoring System as a Diagnostic Aid for the Registration of Distinguishing Marks in the Breeding Program for Lambs Exposed to an Experimental Haemonchus contortus Infection. Dtsch. Tierarztl. Wochenschr. 2004, 111, 430-433.

32. Koopmann, R.; Holst, C.; Epe, C. Experiences with the FAMACHA ${ }^{\odot}$-Eye-Colour-Chart for Identifying Sheep and Goats for Targeted Anthelmintic Treatment. Berl. Und Müncher Tierärztliche Wochenschr. 2006, 119, 436-442.

33. Papadopoulos, E.; Gallidis, E.; Ptochos, S.; Fthenakis, G. Evaluation of the FAMACHA ${ }^{\odot}$ System for Targeted Selective Anthelmintic Treatments for Potential Use in Small Ruminants in Greece. Small Rumin. Res. 2013, 110, 124-127. [CrossRef]

34. Di Loria, A.; Veneziano, V.; Piantedosi, D.; Rinaldi, L.; Cortese, L.; Mezzino, L.; Cringoli, G.; Ciaramella, P. Evaluation of the FAMACHA System for Detecting the Severity of Anaemia in Sheep from Southern Italy. Vet. Parasitol. 2009, 161, 53-59. [CrossRef]

35. Reynecke, D.P.; Van Wyk, J.A.; Gummow, B.; Dorny, P.; Boomker, J. Validation of the FAMACHA ${ }^{\odot}$ Eye Colour Chart Using Sensitivity/Specificity Analysis on Two South African Sheep Farms. Vet. Parasitol. 2011, 177, 203-211. [CrossRef]

36. Scheuerle, M.; Mahling, M.; Muntwyler, J.; Pfister, K. The Accuracy of the FAMACHA ${ }^{\odot}$-Method in Detecting Anaemia and Haemonchosis in Goat Flocks in Switzerland Under Field Conditions. Vet. Parasitol. 2010, 170, 71-77. [CrossRef]

37. Kaplan, R.; Burke, J.; Terrill, T.; Miller, J.; Getz, W.; Mobini, S.; Valencia, E.; Williams, M.; Williamson, L.; Larsen, M. Validation of the FAMACHA@ Eye Color Chart for Detecting Clinical Anemia in Sheep and Goats on Farms in the Southern United States. Vet. Parasitol. 2004, 123, 105-120. [CrossRef]

38. Olah, S.; van Wyk, J.A.; Wall, R.; Morgan, E.R. FAMACHA®: A Potential Tool for Targeted Selective Treatment of Chronic Fasciolosis in Sheep. Vet. Parasitol. 2015, 212, 188-192. [CrossRef] 
39. Grace, D.; Himstedt, H.; Sidibe, I.; Randolph, T.; Clausen, P.-H. Comparing FAMACHA ${ }^{\circledR}$ Eye Color Chart and Hemoglobin Color Scale Tests for Detecting Anemia and Improving Treatment of Bovine Trypanosomosis in West Africa. Vet. Parasitol. 2007, 147, 26-39. [CrossRef] [PubMed]

40. Viesselmann, L.C.; Videla, R.; Schaefer, J.; Chapman, A.; Wyrosdick, H.; Schaefer, D.M. Mycoplasma haemolamae and Intestinal Parasite Relationships With Erythrocyte Variables in Clinically Healthy Alpacas and Llamas. J. Vet. Intern. Med. 2019, 33, 2336-2342. [CrossRef] [PubMed]

41. Cocquyt, C.M.; Van Amstel, S.; Cox, S.; Rohrbach, B.; Martín-Jiménez, T. Pharmacokinetics of Moxidectin in Alpacas Following Administration of an Oral or Subcutaneous Formulation. Res. Vet. Sci. 2016, 105, 160-164. [CrossRef] [PubMed]

42. Galvan, N.; Middleton, J.R.; Nagy, D.W.; Schultz, L.G.; Schaeffer, J.W. Anthelmintic Resistance in a Herd of Alpacas (Vicugna Pacos). Can. Vet. J. 2012, 53, 1310. [PubMed]

43. Viesselmann, L.C.; Videla, R.; Flatland, B. Verification of the Heska Element Point-of-Care Blood Gas Instrument for Use with Venous Blood From Alpacas and Llamas, With Determination of Reference Intervals. Vet. Clin. Pathol. 2018, 47, 435. [CrossRef]

44. Gauly, M.; Maier, H.; Trah, M. Blood Collection, Haematological Values, Biochemical Parameters of New World Camelids. Tierärztliche Umsch. 1998, 53, 751-754.

45. Wagener, M.G.; Grossmann, T.; Stöter, M.; Ganter, M. Hematological Diagnostics in Llamas and Alpacas. Der Prakt. Tierarzt 2018, 99, 481-493.

46. Hengrave Burri, I.; Tschudi, P.; Martig, J.; Liesegang, A.; Meylan, M. South American Camelids in Switzerland. II. Reference Values for Blood Parameters. Schweiz. Arch. Für Tierheilkd. 2005, 147, 335-343. [CrossRef] [PubMed]

47. Maia, D.; Rosalinski-Moraes, F.; Van Wyk, J.A.; Weber, S.; Sotomaior, C.S. Assessment of a Hands-On Method for FAMACHA ${ }^{\circledR}$ System Training. Vet. Parasitol. 2014, 200, 165-171. [CrossRef] [PubMed]

48. Rafia, S.; Taghipour-Bazargani, T.; Khaki, Z.; Bokaie, S.; Tabrizi, S.S. Effect of Body Condition Score on Dynamics of Hemogram in Periparturient Holstein Cows. Comp. Clin. Pathol. 2012, 21, 933-943. [CrossRef]

49. Torres-Chable, O.M.; García-Herrera, R.A.; González-Garduño, R.; Ojeda-Robertos, N.F.; Peralta-Torres, J.A.; Chay-Canul, A.J. Relationships Among Body Condition Score, FAMACHA ${ }^{\circledR}$ Score and Haematological Parameters in Pelibuey Ewes. Trop. Anim. Health Prod. 2020, 52, 3403-3408. [CrossRef]

50. Munoz, A.; Riber, C.; Trigo, P.; Castejon, F. Hematology and Clinical Pathology Data in Chronically Starved Horses. J. Equine Vet. Sci. 2010, 30, 581-589. [CrossRef]

51. Weiser, M.; Fettman, M.; Van Houten, D.; Johnson, L.; Garry, F. Characterization of Erythrocytic Indices and Serum Iron Values in Healthy Llamas. Am. J. Vet. Res. 1992, 53, 1776-1779.

52. Hajduk, P. Haematological Reference Values for Alpacas. Aust. Vet. J. 1992, 69, 89-90. [CrossRef]

53. Fowler, M.; Zinkl, J. Reference Ranges for Hematologic and Serum Biochemical Values in Llamas (Lama glama). Am. J. Vet. Res. 1989, 50, 2049-2053.

54. Al-Izzi, S.; Abdouslam, O.; Al-Bassam, L.; Azwai, S. Haematological Parameters in Clinically Normal Llamas (Lama glama). Prax. Vet. 2004, 52, 225-232.

55. Husakova, T.; Pavlata, L.; Pechova, A.; Tichy, L.; Hauptmanova, K. The Influence of Sex, Age and Season on the Haematological Profile of Alpacas (Vicugna pacos) in Central Europe. Vet. Med. 2015, 60, 407-414. [CrossRef]

56. Goggs, R. Normoblasts: Not Always Normal. Vet. Rec. 2014, 175, 506-507. [CrossRef] [PubMed]

57. Wagener, M.G.; Puff, C.; Stöter, M.; Schwennen, C.; Ganter, M. Regenerative Anaemia in Alpacas (Vicugna pacos) Can Lead to a Wrong Diagnosis of Leucocytosis. Vet. Rec. Case Rep. 2020, 8, e001257. [CrossRef]

58. Newhall, D.A.; Oliver, R.; Lugthart, S. Anaemia: A Disease or Symptom. Neth. J. Med. 2020, 78, 104-110. 